\title{
4-Hydroxytamoxifen induces slight uncoupling of mitochondrial oxidative phosphorylation system in relation to the deleterious effects of tamoxifen
}

\author{
Carla M.P. Cardoso ${ }^{\mathrm{a}, \mathrm{b}}$, António J.M. Moreno ${ }^{\mathrm{b}}$, Leonor M. Almeida ${ }^{\mathrm{a}, \mathrm{b}}$, \\ José B.A. Custódio ${ }^{\mathrm{a}, \mathrm{b}, *}$ \\ a Laboratório de Bioquímica, Faculdade de Farmácia, Universidade de Coimbra, Couraça dos Apóstolos, 51 r/c 3000-295 Coimbra, \\ Portugal \\ ${ }^{\mathrm{b}}$ Centro de Neurociencias de Coimbra, Universidade de Coimbra, Coimbra, Portugal
}

Received 21 March 2002; received in revised form 6 May 2002; accepted 21 June 2002

\begin{abstract}
The use of tamoxifen (TAM) has been questioned on the chemotherapy and chemoprevention of breast cancer due to several estrogen receptor-independent cytotoxic effects. As an alternative, its more active metabolite 4-hydroxytamoxifen (OHTAM) has been proposed with presumed lower side effects. In this work, the potential OHTAM toxicity on rat liver mitochondrial bioenergetics in relation to the multiple deleterious effects of TAM was evaluated. OHTAM, at concentrations lower than those putatively reached in tissues following the administration of TAM, does not induce significant perturbations on the respiratory control ratio (RCR), ADP/O, transmembrane potential $(\Delta \Psi)$, phosphorylative capacity and membrane integrity of mitochondria. However, at high concentrations, OHTAM depresses the $\Delta \Psi, \mathrm{RCR}$ and $\mathrm{ADP} / \mathrm{O}$, affecting the phosphorylation efficiency, as also inferred from the $\Delta \Psi$ fluctuations and $\mathrm{pH}$ changes associated with ADP phosphorylation. Moreover, OHTAM, at concentrations that stimulate the rate of state 4 respiration in parallel to the decrease in the $\Delta \Psi$ and phosphorylation rate, causes mitochondrial swelling and stimulates both ATPase and citrate synthase activities. However, the OHTAM-observed effects, at high concentrations, are not significant relatively to the damaging effects promoted by TAM and suggest alterations to mitochondrial functions due to proton leak across the mitochondrial inner membrane. (C) 2002 Elsevier Science Ireland Ltd. All rights reserved.
\end{abstract}

Keywords: 4-Hydroxytamoxifen; Breast cancer; Mitochondrial bioenergetics; Mitochondrial transmembrane potential; Oxidative phosphorylation efficiency; Proton leak; Membrane permeabilization

Abbreviations: ADP/O ratio, number of ADP molecules added to the medium per oxygen atom consumed during phosphorylation; ANT, adenine nucleotide translocator; BSA, bovine serum albumin; ER, estrogen receptor; EGTA, ethylene glycol-bis ( $\beta$-aminoethyl ether) NNN'N-tetraacetic acid; FCCP, carbonyl cyanide $p$-trifluormethoxyphenylhydrazone; HEPES, 4-(2-hydroxymethyl)-1piperazineethanesulfonic acid; Mops, 3-[ $N$-Morpholino]propanesulfonic acid; OHTAM, 4-hydroxytamoxifen; RCR, respiratory control ratio (= state 3/state 4); SR, sarcoplasmic reticulum; TAM, Tamoxifen; Tris, Tris (hydroxymethyl)-aminomethan; TPP ${ }^{+}$, tetraphenylphosphonium; $\Delta \Psi$, Mitochondrial membrane potential; $\Delta p$, proton motive force.

* Corresponding author. Tel.: +351-239-852564; fax: +351-239-852569

E-mail address: custodio@ci.uc.pt (J.B.A. Custódio). 


\section{Introduction}

Tamoxifen (TAM) is an important adjunct chemotherapeutic agent for treating breast cancer (Early Breast Cancer Trialists' Collaborative Group, 1998). This non-steroidal antiestrogen has also been reported as an effective agent in the chemoprevention of healthy women at high risk of the disease (Ault and Brandbury, 1998). However, TAM causes serious side effects, such as hepatocellular damage and agranulocytosis (Ching et al., 1992), increased risk of uterine and endometrial cancers (Ault and Brandbury 1998; Early Breast Cancer Trialists' Collaborative Group, 1998), hemolytic anemia (Ching et al., 1992; Suwalsky et al., 1998), inhibition of $\mathrm{Ca}^{2+}$ uptake by sarcoplasmic reticulum (SR) (Custódio et al., 1996; Kargacin et al., 2000) and erythrocyte hemolysis (Cruz Silva et al., 2000). Therefore, an alternative breast cancer treatment with presumed lower side effects, such as the percutaneous administration of 4-hydroxytamoxifen (OHTAM), the major active metabolite of TAM and responsible for its antiestrogenic activity, has already been performed (Mauvais-Jarvis et al., 1986).

Previous studies have reported that, in comparison with TAM, OHTAM has higher affinity and specificity for the estrogen receptor (ER) (Borgna and Rochefort, 1981) and, besides being 100- to 200- times more potent (Osborne et al., 1992; Jordan et al., 1988), it is pharmacologically well tolerated (Sauvez et al., 1999) and less toxic to erythrocytes (Cruz Silva et al., 2001) and to the SR calcium pump (Custódio et al., 1996). Furthermore, in contrast to TAM, OHTAM fails to induce either mitochondrial depolarization or caspase activation and, subsequently, does not induce apoptosis in p53(-) human mammary epithelial cells [p53(-)HMEC] (Dietze et al., 2001). Despite these and other studies, including those reporting the differences between the $\mathrm{OH}-$ TAM percutaneous and oral administration (Pujol et al., 1995; Sauvez et al., 1999), the toxicity mechanisms of OHTAM are not yet clarified. Therefore, toxicological studies are required to assure a safe and appropriate administration of OHTAM on breast cancer therapy and to achieve a better understanding of the molecular pharmacology of this drug.

Mitochondria are important subcellular sites recognized as energy generators for the cell, as well as control points of cell replication, differentiation, ion regulation and other active transport processes of intermediary metabolism (Wallace et al., 1997; Wallace and Starkov, 2000). Moreover, recent studies have demonstrated that mitochondria play a key role in cell signaling and in the apoptotic cell death (Loeffler and Kroemer, 2000). Consequently, changes in the structural and functional characteristics of mitochondria provide a number of primary targets for xenobiotic-induced toxicity and cell death (Wallace and Starkov, 2000). Therefore, in addition to the different effects reported for TAM and its metabolite OHTAM on mitochondria structure and apoptosis of p53(-)HMEC cells (Dietze et al., 2001), the evaluation of OHTAM effects on mitochondrial bioenergetic functions are important to a better understanding of its molecular action mechanisms and potential mitochondrial toxicity in relation to the damaging effects of TAM (Cardoso et al., 2001).

\section{Materials and methods}

\subsection{Chemicals}

OHTAM, bovine serum albumin (BSA), 4-(2hydroxymethyl)-1-piperazineethanesulfonic acid (HEPES), ethylene glycol-bis ( $\beta$-aminoethyl ether) NNN'N-tetraacetic acid (EGTA), 3-[ $N$-Morpholino]propanesulfonic acid (Mops), 5,5'-dithiobis(2-nitrobenzoic acid), oxaloacetic acid, acetylcoA, nigericin and oligomycin were purchased from Sigma Chemical Co (St. Louis, MO). Tris (hydroxymethyl)-aminomethan (Tris), tetraphenylphosphonium $\left(\mathrm{TPP}^{+}\right)$, carbonyl cyanide $p$ trifluormethoxyphenylhydrazone (FCCP) and sucrose were obtained from Merck (Dramstadt, Germany). All other chemicals were commercial products of the highest purity grade available and solutions were prepared in deionized ultra pure water. 


\subsection{Preparation of rat liver mitochondria}

Mitochondria were isolated from the liver of overnight fasted Wistar rats $(250-300 \mathrm{~g})$ of either sex by differential centrifugation as described elsewhere (Custódio et al., 1998), with slight modifications. Animals were killed by decapitation and the liver was quickly homogenized. The homogenate was prepared in $250 \mathrm{mM}$ sucrose, 10 mM HEPES (pH 7.4), 1 mM EGTA and 0.1\% (w/ v) free fatty acid BSA. The liver homogenate was centrifuged at $500 \times g$ for $10 \mathrm{~min}$ at $4{ }^{\circ} \mathrm{C}$ and mitochondria were recovered from the supernatant by centrifugation at $10000 \times g$ for $10 \mathrm{~min}$. The mitochondrial pellet was resuspended twice in the washing medium containing $250 \mathrm{mM}$ sucrose, 10 $\mathrm{mM}$ HEPES, pH 7.2. Mitochondrial protein was determined by the biuret method using BSA as the standard (Gornall et al., 1949).

\subsection{Mitochondrial membrane potential measurements}

Mitochondrial membrane potential $(\Delta \Psi)$ was estimated by calculating transmembrane distribution of $\mathrm{TPP}^{+}$with a $\mathrm{TPP}^{+}$-selective electrode prepared according to Kamo et al. (1979), using a $\mathrm{Ag} / \mathrm{AgCl}$-saturated electrode as reference (model MI 402; Microelectrodes, Inc., Bedford, NH). $\Delta \Psi$ is expressed in $\mathrm{mV}$ and $\mathrm{TPP}^{+}$uptake was measured from the decreased $\mathrm{TPP}^{+}$concentration in the medium sensed by the electrode. The differences between the selective and the reference electrodes were measured with an electrometer and were recorded continuously (Kamo et al., 1979; Moreno and Madeira, 1991). Reactions were carried out in a closed chamber at $25{ }^{\circ} \mathrm{C}$, with magnetic stirring in $1 \mathrm{ml}$ of standard respiratory medium $(130 \mathrm{mM}$ sucrose, $50 \mathrm{mM} \mathrm{KCl}, 2.5 \mathrm{mM}$ $\mathrm{MgCl}_{2}, 2.5 \mathrm{mM} \mathrm{KH} \mathrm{PO}_{4}, 5 \mathrm{mM}$ HEPES and 0.1 mM EGTA) supplemented with $2 \mu \mathrm{M}$ rotenone and $4 \mu \mathrm{M} \mathrm{TPP}^{+}$. OHTAM was added from ethanolic solutions to mitochondria $(1 \mathrm{mg})$ and pre-incubated for $3 \mathrm{~min}$ before the addition of 5 $\mathrm{mM}$ succinate to ensure the complete incorporation of the compound into the membrane due to its lipophilic characteristics (Custódio et al., 1991). After reaching a steady-state distribution of
$\mathrm{TPP}^{+}$, ADP (150 nmol/mg protein) was added. Preliminary calibrations run in the presence of OHTAM excluded any direct interference of the drug with the electrode signal.

\subsection{Mitochondrial respiration}

The oxygen consumption (respiration rate) of isolated mitochondria was measured polarographically using a Clark-type oxygen electrode (YSI model 5331, Yellow Spring Inst.), in a $1 \mathrm{ml}$ thermostated water-jacketed closed chamber with magnetic stirring and connected to a suitable recorder. OHTAM in ethanolic solutions (up to $3 \mu \mathrm{l}$ ) was incubated for $3 \mathrm{~min}$ at $25^{\circ} \mathrm{C}$ in $1 \mathrm{ml}$ of the standard respiratory medium previously supplemented with mitochondria $(1 \mathrm{mg})$ and $2 \mu \mathrm{M}$ rotenone. State 4 respiration was initiated with 5 $\mathrm{mM}$ succinate and ADP $(150 \mathrm{nmol} / \mathrm{mg}$ protein $)$ was added to establish state 3 respiration. Respiration rates were calculated assuming an oxygen concentration of $240 \mathrm{nmol} \mathrm{O}_{2} / \mathrm{ml}$ in the experimental medium at $25{ }^{\circ} \mathrm{C}$. Respiratory control ratio $(\mathrm{RCR}=$ state $3 /$ state 4$)$, respiratory rates, and ADP/O ratios (number of ADP molecules added to the medium per oxygen atom consumed during phosphorylation) were calculated according to Chance and Williams (1956).

\subsection{Simultaneous measurements of respiration rate and $\Delta \Psi$}

In order to determine the effects of OHTAM on mitochondrial function and to discriminate its site of action on mitochondria we adopted the approach commonly used for top-down metabolic control analysis (Brand, 1990; Hafner et al., 1990; Lionetti et al., 1998). With this approach, oxidative phosphorylation is conceptually divided into three subsystems, i.e., mitochondrial respiratory chain, phosphorylation system and the proton leak. To assess the effects of OHTAM on the proton motive force $(\Delta p)$ producing system (the respiratory chain complexes and the substrate transporters), mitochondrial respiration and $\Delta \Psi$ were measured simultaneously at $25{ }^{\circ} \mathrm{C}$ in a $1-\mathrm{ml}$ incubation chamber fitted with a Clark-type oxygen electrode and a $\mathrm{TPP}^{+}$sensitive electrode. 
Mitochondria (1 $\mathrm{mg}$ ) were suspended in the reaction medium containing $130 \mathrm{mM}$ sucrose, $100 \mathrm{mM} \mathrm{KCl}, 2.5 \mathrm{mM} \mathrm{MgCl}, 2.5 \mathrm{mM} \mathrm{KH}_{2} \mathrm{PO}_{4}$, $5 \mathrm{mM}$ HEPES and $0.1 \mathrm{mM}$ EGTA, supplemented with $2 \mu \mathrm{M}$ rotenone, $4 \mu \mathrm{M} \mathrm{TPP}^{+}, 1 \mu \mathrm{g}$ oligomycin (to eliminate phosphorylation) and $50 \mathrm{ng}$ nigericin, which was used to collapse the $\mathrm{pH}$ gradient across the mitochondrial inner membrane (Murphy and Brand, 1987; Hafner and Brand, 1991), making the $\Delta \Psi$ the sole component of $\Delta p$. Mitochondria were incubated under these conditions for $3 \mathrm{~min}$ in the presence of OHTAM. Respiration was initiated by the addition of $5 \mathrm{mM}$ succinate and after a steadystate $\mathrm{TPP}^{+}$distribution the titration was performed by successive additions of FCCP (10 $\mathrm{nM})$, according to previously described procedures (Brand, 1990; Lionetti et al., 1998). The same protocol was followed to assess the effects of OHTAM on proton leak (i.e. the passive permeability of the inner mitochondrial membrane to protons and any cation cycling reactions), but the titration was done with successive additions of malonate $(0.5 \mathrm{mM})$. Titration experiments with OHTAM were conducted under similar conditions in the absence of either FCCP or malonate.

\subsection{Measurement of mitochondrial swelling}

Mitochondrial osmotic volume changes were followed by monitoring the decrease in absorbance (light-scattering) at $540 \mathrm{~nm}$ (Custódio et al., 1998) with a Perkin Elmer, Lambda 6 UV/VIS spectrophotometer. The reactions were performed with 1 $\mathrm{mg}$ mitochondrial protein in $2 \mathrm{ml}$ of a reaction medium containing $200 \mathrm{mM}$ sucrose, $10 \mathrm{mM}$ Tris-

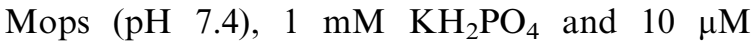
EGTA. OHTAM and TAM were added to mitochondrial suspensions in the absence of respiratory substrates and preincubated for $3 \mathrm{~min}$ at $30{ }^{\circ} \mathrm{C}$.

\subsection{Enzymatic activities}

ATPase activity was estimated by monitoring the $\mathrm{pH}$ changes of the medium associated with ATP hydrolysis (Madeira et al., 1974). The experiments were carried out at $25{ }^{\circ} \mathrm{C}$ in $2 \mathrm{ml}$ of the standard respiratory medium lightly buffered containing $0.5 \mathrm{mM}$ HEPES, $130 \mathrm{mM}$ sucrose, $50 \mathrm{mM}$
$\mathrm{KCl}, 2.5 \mathrm{mM} \mathrm{MgCl} 2,5 \mathrm{mM} \mathrm{KH_{2 }} \mathrm{PO}_{4}, 0.1 \mathrm{mM}$ EGTA, pH 7.2 and supplemented with $2 \mu \mathrm{M}$ rotenone. OHTAM and TAM were incubated with mitochondria ( $1 \mathrm{mg}$ ) for $3 \mathrm{~min}$ before starting the reactions with Mg-ATP as described elsewhere (Ferreira et al., 1997). Oligomycin (1 $\mu \mathrm{g} / \mathrm{mg}$ protein) was added $1.5 \mathrm{~min}$ after starting the reactions.

ATP-synthase activity was determined by measuring the $\mathrm{pH}$ changes of the medium associated with ATP synthesis as reported by Moreno and Madeira (1991), at $25{ }^{\circ} \mathrm{C}$, in $2 \mathrm{ml}$ of reaction medium containing $130 \mathrm{mM}$ sucrose, $50 \mathrm{mM} \mathrm{KCl}$, $2.5 \mathrm{mM} \mathrm{MgCl}_{2}, 5 \mathrm{mM} \mathrm{KH} \mathrm{PO}_{4}, 0.5 \mathrm{mM}$ HEPES, $0.1 \mathrm{mM}$ EGTA, pH 7.2, supplemented with $2 \mu \mathrm{M}$ rotenone, $100 \mu \mathrm{M}$ ADP and mitochondria $(1 \mathrm{mg})$. The experiments were initiated by the addition of 5 $\mathrm{mM}$ succinate. TAM and OHTAM, in ethanolic solutions, were added and allowed to incubate with mitochondria for $3 \mathrm{~min}$ before starting the reactions.

Citrate synthase activity was monitored by the increase in absorbance at $412 \mathrm{~nm}$ as previously described (Shepherd and Garland, 1969; Trounce et al., 1996), using a Perkin Elmer, Lambda 6 UV/ VIS spectrophotometer. The reactions were performed with $100 \mu \mathrm{g}$ of mitochondrial protein suspended in $2 \mathrm{ml}$ of the reaction medium contain-

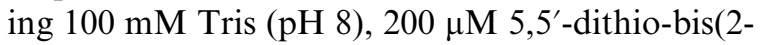
nitrobenzoic acid) and $200 \mu \mathrm{M}$ acetylCoA. The assays were started by the addition of $100 \mu \mathrm{M}$ oxaloacetic acid after incubation of mitochondria in the absence and presence of either $0.1 \%$ Triton $\mathrm{X}-100$, TAM or OHTAM for $3 \mathrm{~min}$ at $30{ }^{\circ} \mathrm{C}$.

\section{Results}

To assess whether OHTAM affects mitochondrial bioenergetic functions, we evaluated the respiration parameters, both the RCR and ADP/ $O$ ratio (Fig. 1), and the $\Delta \Psi$ (Fig. 2) of mitochondria energized with succinate. OHTAM pre-incubated with mitochondria progressively decreases $\mathrm{RCR}$ and ADP/O ratios as a function of concentration (Fig. 1). However, both ratios are not significantly affected by OHTAM as opposed to the high decrease observed at much lower concen- 


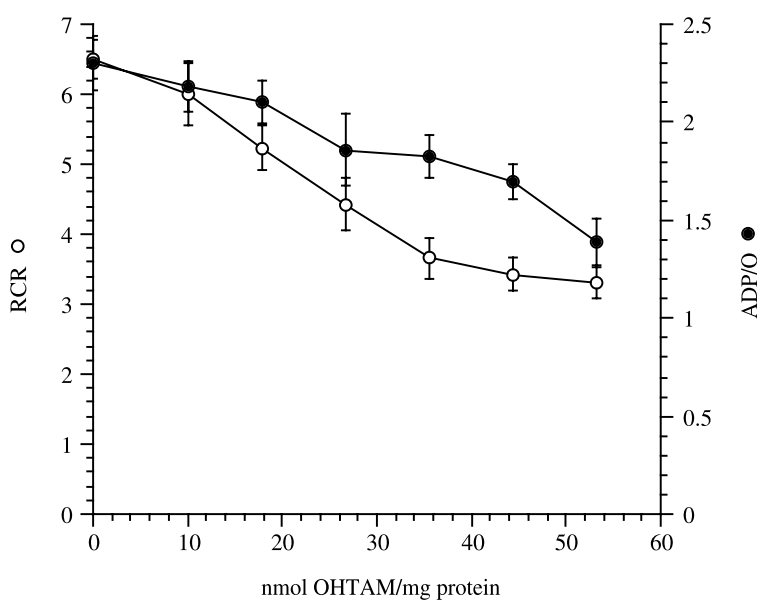

Fig. 1. Effects of OHTAM on mitochondrial RCR $(\bigcirc)$ and $\mathrm{ADP} / \mathrm{O}(-)$ ratio. Mitochondria (1 mg) in $1 \mathrm{ml}$ of the standard respiratory medium supplemented with $2 \mu \mathrm{M}$ rotenone were incubated with different OHTAM concentrations for $3 \mathrm{~min}$ prior to succinate addition (state 4). After $2 \mathrm{~min}$ of energization, mitochondria were supplemented with ADP $(150 \mathrm{nmol} / \mathrm{mg}$ protein) to induce state 3 conditions. Mitochondrial respiration rates were determined by $\mathrm{O}_{2}$ consumption using a Clark-type electrode. Both indexes were calculated as described in Section 2 . The results are means \pm SD of four independent experiments.

trations of TAM (Cardoso et al., 2001). Additionally, OHTAM at concentrations up to $70 \mathrm{nmol} / \mathrm{mg}$ protein does not yet induce complete uncoupling of mitochondria (Figs. 1 and 2). In contrast, TAM induces such drastic effect at $40 \mathrm{nmol} \mathrm{TAM} / \mathrm{mg}$ protein (Cardoso et al., 2001), suggesting that OHTAM is much less toxic to mitochondrial membrane than TAM.

The effects of several concentrations of OHTAM on $\Delta \Psi$ fluctuations associated with either the mitochondrial respiration or the phosphorylation cycle induced by ADP are shown in Fig. 2. Under succinate energization, mitochondria build up a potential of about $-220 \mathrm{mV}$ (negative inside). Upon ADP addition (150 nmol/mg protein), to initiate state 3 respiration (synthesis of ATP), the potential drops immediately to $-190 \mathrm{mV}$, since the phosphorylation system consumes $\Delta \Psi$ to transport and to phosphorylate ADP. After a short lag phase, when the phosphorylation cycle is completed, the transmembrane potential returns to nearly its initial value. OHTAM, at concentrations lower than those putatively reached in tissues following the admin- istration of TAM (McCague et al., 1990; Jordan, 1990; Lien et al., 1991), slightly depresses the $\Delta \Psi$ and the depolarization after ADP addition. However, at high concentrations ( $>40 \mathrm{nmol} / \mathrm{mg}$ protein), the lag phase preceding repolarization displays a marked increase and the rate of repolarization progressively decreases (Fig. 2), suggesting that OHTAM affects the efficiency of the mitochondrial phosphorylative system. These effects become more pronounced at higher OHTAM concentrations whereas TAM, at much lower concentrations, induces a drastic depolarization of $\Delta \Psi$ and total uncoupling of mitochondria, making them unable to phosphorylate the added ADP (Cardoso et al., 2001). This is evidenced in Fig. 3 that shows the effects of both drugs on $\mathrm{pH}$ changes associated with ATP synthesis. Thus, the consequences of OHTAM on the phosphorylation cycle induced by ADP, as shown in Fig. 2, are consistent with those on ADP/O ratio (Fig. 1) and with the promoted decrease in the rate of ATP synthesis by intact mitochondria (Fig. 3). In fact, increasing concentrations of OHTAM depress the rate of ATP synthesis, increasing the time required to phosphorylate the ADP $(200 \mathrm{nmol} / \mathrm{mg}$ protein) (Fig. 3). However, it is noteworthy that $\mathrm{TAM}$, at a concentration of $50 \mathrm{nmol} / \mathrm{mg}$ protein, completely inhibits the phosphorylation of the added ADP, in contrast to OHTAM that at the same concentration only decreases the rate of phosphorylation (Fig. 3).

A simultaneous follow-up of OHTAM effects on both $\Delta \Psi$ and state 4 respiration (Fig. 4) shows that sequential additions of this drug to mitochondria causes a small decrease in $\Delta \Psi$ and a parallel stimulation of state 4 respiration to compensate the induced depolarization of $\Delta \Psi$. Subsequent additions of OHTAM lead to a lower stimulation of respiration rate, concomitantly with a significant depolarization of $\Delta \Psi$ (results not shown).

In agreement with the depolarization of $\Delta \Psi$ (Fig. 2) and the stimulation of state 4 (Fig. 4) caused by a proton leak through the mitochondrial inner membrane, OHTAM increases the ATPase activity of tightly coupled intact mitochondria (Fig. 5). However, these effects are smaller than those promoted by TAM, which induces disruption of the mitochondrial inner membrane integ- 


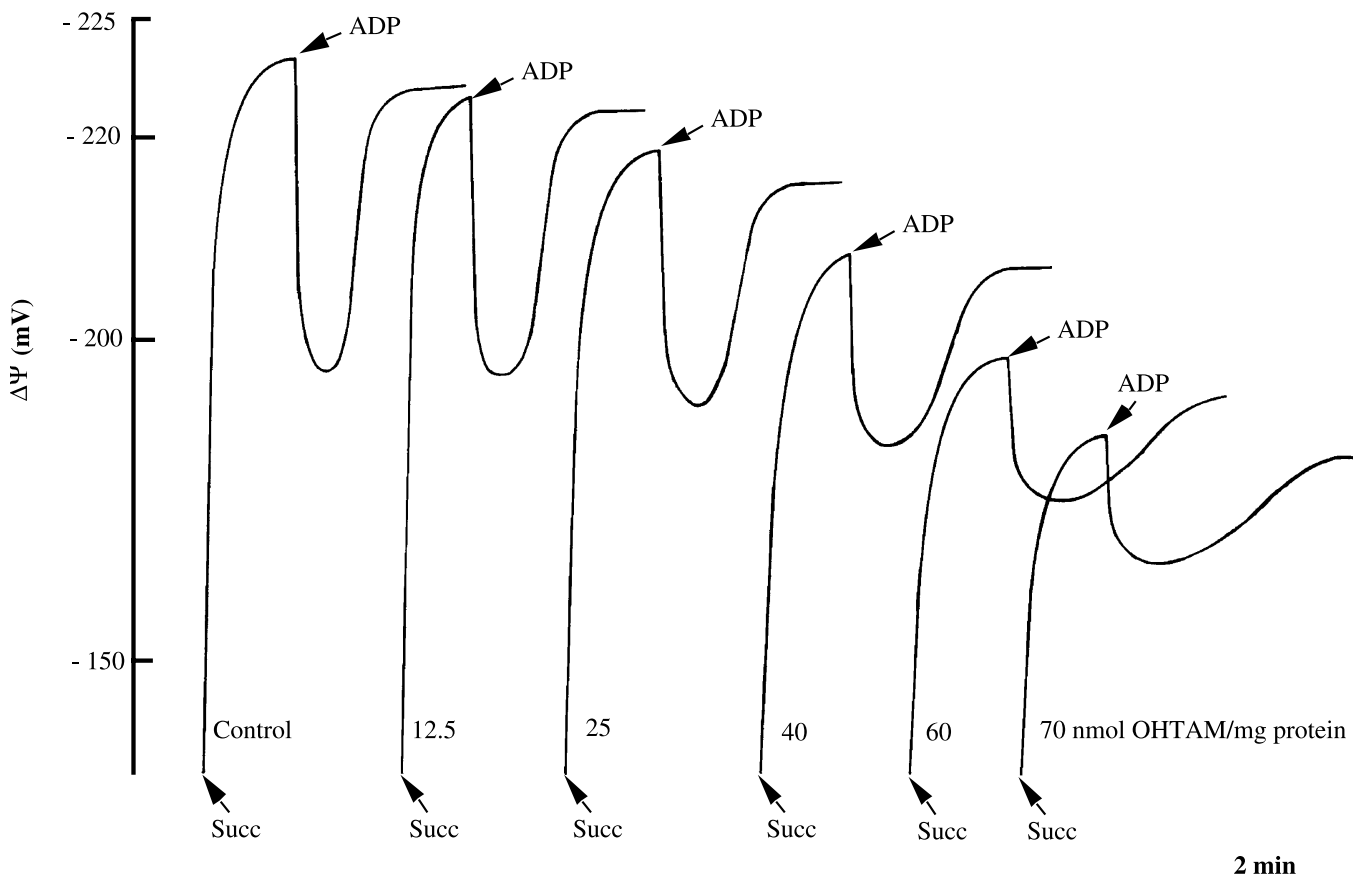

Fig. 2. Effect of OHTAM on mitochondrial transmembrane potential $(\Delta \Psi)$. Mitochondria $(1 \mathrm{mg})$ incubated for $3 \mathrm{~min}$ in $1 \mathrm{ml}$ standard respiratory medium supplemented with $2 \mu \mathrm{M}$ rotenone and $4 \mu \mathrm{M} \mathrm{TPP}{ }^{+}$were energized with succinate after incubation at $25{ }^{\circ} \mathrm{C}$ for 3 min in the absence (control) and presence of different OHTAM concentrations (nmol/mg protein) indicated by the numbers adjacent to the traces. Addition of ADP $(150 \mathrm{nmol} / \mathrm{mg}$ protein $)$ induces state 3 conditions. $\Delta \Psi$ was determined using a TPP ${ }^{+}$-sensitive electrode as described in Section 2. The traces represent typical recordings from four to six experiments with different mitochondrial preparations.

rity, as evidenced in Fig. 5 and further in Fig. 8 and Fig. 9.

To clarify the mechanisms responsible for the stimulation of state 4 respiration and $\Delta \Psi$ depolarization, the effects of OHTAM on mitochondria were evaluated according to the approach developed by Brand (1990) (Fig. 6). This approach has been pointed to be useful to determine how compounds of pharmacological interest affect the mitochondria (Fusi et al., 1992). Nonphosphorylating mitochondria (in the presence of oligomycin) were titrated with FCCP to promote an increase in respiratory rate and a decrease in $\Delta \Psi$. The plot of $\Delta \Psi$ versus respiration rate describes the kinetic response of the $\Delta p$ generators to $\Delta \Psi$ (Brand, 1990) (Fig. 6). If a compound inhibits the respiratory chain, this curve will be displaced downward and to the left (Brand, 1990). Fig. 6 shows $\Delta \Psi$ changes versus the respiration rate obtained in the absence (control) and in the presence of several concentrations of OHTAM (20, 40 and $60 \mathrm{nmol}$ OHTAM/mg protein). At any given value of $\Delta \Psi$, OHTAM induces a slight decrease in the respiration rate. The displacement of the curve induced by OHTAM indicates that one or more components of the $\Delta p$ generating system are slightly inhibited by this drug, in contrast with the severe effects induced by TAM on the respiratory chain (Cardoso et al., 2001).

The putative proton leaks induced by OHTAM through the mitochondrial inner membrane were investigated in nonphosphorylating mitochondria titrated with malonate, a respiratory inhibitor, and $\Delta \Psi$ was plotted versus respiration rate (Fig. 7). In the steady state, the proton efflux must equal the proton leak, assuming that no slip in the proton pump occurs (Murphy, 1989) and any secondary effects on the leak due to alterations in the $\Delta p$ value were eliminated. When a compound increases the proton leak across the mitochondrial 


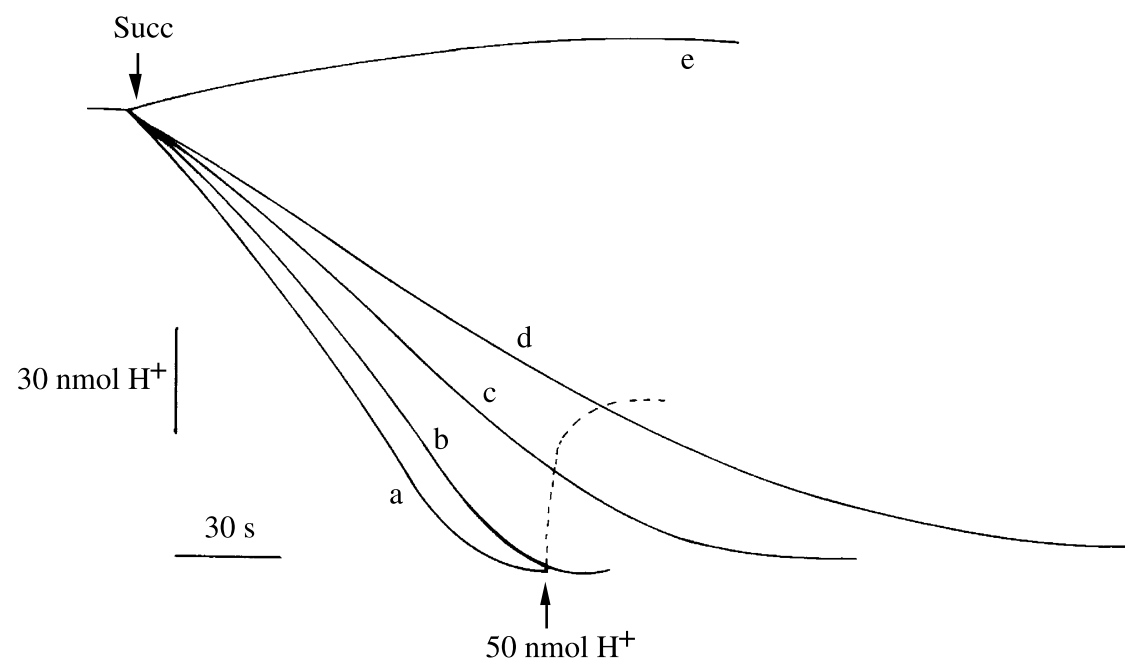

Fig. 3. Effects of OHTAM and TAM on pH changes associated with ATP synthesis. The ATP synthesis was evaluated at $25{ }^{\circ} \mathrm{C}$ in 2 $\mathrm{ml}$ of reaction medium containing $130 \mathrm{mM}$ sucrose, $50 \mathrm{mM} \mathrm{KCl}, 2.5 \mathrm{mM} \mathrm{MgCl}, 5 \mathrm{mM} \mathrm{KH}_{2} \mathrm{PO}_{4}, 0.5 \mathrm{mM}$ HEPES, $0.1 \mathrm{mM}$ EGTA (pH 7.2), supplemented with $2 \mu \mathrm{M}$ rotenone and $200 \mathrm{nmol}$ ADP. Mitochondria ( $1 \mathrm{mg}$ ) were incubated for 3 min in the absence (a) and presence of 20 (b), 40 (c) and 50 (d) nmol OHTAM/mg protein or $50 \mathrm{nmol} \mathrm{TAM} / \mathrm{mg}$ protein (e). The reactions were started by adding 5 $\mathrm{mM}$ succinate and were monitored by following the consumption of protons with a $\mathrm{pH}$ electrode. The traces are typical of four different experiments.

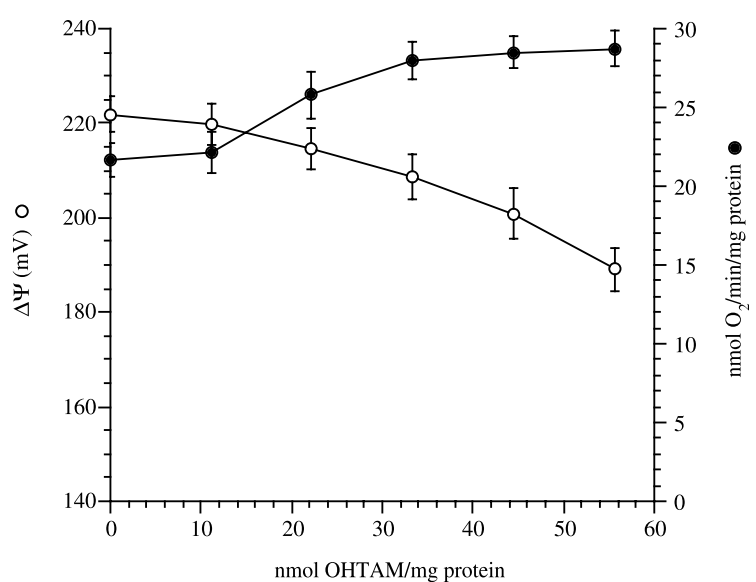

Fig. 4. Effect of sequential additions of OHTAM on $\Delta \Psi(\bigcirc)$ and state 4 respiration $(\bullet)$ in non-phosphorylating mitochondria. Mitochondria $(1 \mathrm{mg})$ were suspended in $1 \mathrm{ml}$ of the standard respiratory medium supplemented with nigericin (50 $\mathrm{ng} / \mathrm{mg}$ protein), oligomycin $(1 \mu \mathrm{g} / \mathrm{ml}), 2 \mu \mathrm{M}$ rotenone and $4 \mu \mathrm{M}$ $\mathrm{TPP}^{+}$at $25{ }^{\circ} \mathrm{C}$ and were energized with $5 \mathrm{mM}$ succinate. Mitochondrial respiration rates and $\Delta \Psi$ were evaluated simultaneously using a Clark-type electrode and a $\mathrm{TPP}^{+}$selective electrode, respectively, placed in the same reaction chamber. After steady-state distribution of $\mathrm{TPP}^{+}$, the mitochondrial suspension was titrated with sequential additions of $10 \mathrm{nmol}$ OHTAM/mg protein. The results are means \pm SD of three separate experiments with different mitochondrial preparations. inner membrane, the curve will be displaced downward and to the right (Brand, 1990). Accordingly, OHTAM increases the proton leak across the mitochondrial inner membrane (Fig. 7) since at any given $\Delta \Psi$ value the respiration rate is greater in the presence of the antiestrogen to balance the back flow of protons across the mitochondrial inner membrane. It is noteworthy that the $\mathrm{OH}$ TAM-induced membrane permeabilization to protons is lower than that induced by TAM, according to its effects on biomembranes, as previously reported (Custódio et al., 1996; Cruz Silva et al., 2001). Actually, in the presence of 20 $\mathrm{nmol} \mathrm{TAM} / \mathrm{mg}$ protein, the respiratory rate of mitochondria to sustain $-190 \mathrm{mV}$ is about 32 nmol $\mathrm{O}_{2} / \mathrm{min} / \mathrm{mg}$ protein, a value about 3 times higher than that observed at the same concentration of OHTAM and similar to that induced by 60 nmol OHTAM/mg protein (Fig. 7).

In order to clarify whether the proton permeabilization is a consequence of either mitochondrial membrane disruption or proton shuttling, the effects of OHTAM on the integrity of the mitochondrial membrane of intact non-energized mitochondria were evaluated. OHTAM causes a 


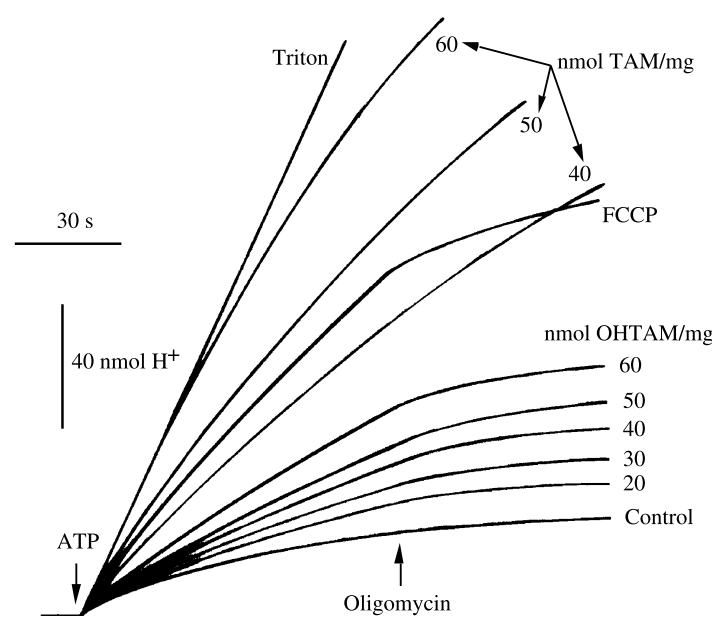

Fig. 5. Comparison of OHTAM and TAM effects on ATPase of intact mitochondria. The ATPase activity was evaluated at $25{ }^{\circ} \mathrm{C}$ in $2 \mathrm{ml}$ of reaction medium containing $130 \mathrm{mM}$ sucrose, $50 \mathrm{mM} \mathrm{KCl}, 2.5 \mathrm{mM} \mathrm{MgCl}_{2}, 5 \mathrm{mM} \mathrm{KH}_{2} \mathrm{PO}_{4}, 0.5 \mathrm{mM}$ HEPES, $0.1 \mathrm{mM}$ EGTA (pH 7.2) and supplemented with $2 \mu \mathrm{M}$ rotenone. After pre-incubation of mitochondria $(1 \mathrm{mg})$ for 3 min with different concentrations of OHTAM or TAM (nmol/ mg protein), as indicated by the values adjacent to the traces, the reactions were started by adding $2 \mathrm{mM} \mathrm{Mg-ATP}$ and were monitored by following the production of protons with a $\mathrm{pH}$ electrode. Oligomycin $(1 \mu \mathrm{g} / \mathrm{mg}$ protein) was added $1.5 \mathrm{~min}$ after Mg-ATP addition. The traces are typical of three different experiments.

small dose-dependent decrease in the light scattering of non-energized mitochondria in suspension (Fig. 8), reflecting a slight direct effect of this drug on mitochondrial membrane integrity. Such effect becomes more evident at OHTAM proportions above $40 \mathrm{nmol} / \mathrm{mg}$ mitochondrial protein, suggesting that this drug only at high concentrations may interfere with the integrity of mitochondrial membranes, perturbing their permeability. However, these effects are not significant relatively to those induced by TAM, which at $50 \mathrm{nmol} / \mathrm{mg}$ protein causes an extensive swelling of mitochondria. The assessment of mitochondria integrity was further confirmed by using the accessibility of citrate synthase from matrix to oxaloacetic acid through the mitochondrial membrane (Fig. 9). According to that observed in mitochondrial swelling studies (Fig. 8), increasing concentrations of OHTAM induce relative slight effects on mitochondrial integrity, since proportions of 10,25 and 50 $\mathrm{nmol} / \mathrm{mg}$ protein only affect 13,17 and $40 \%$ of

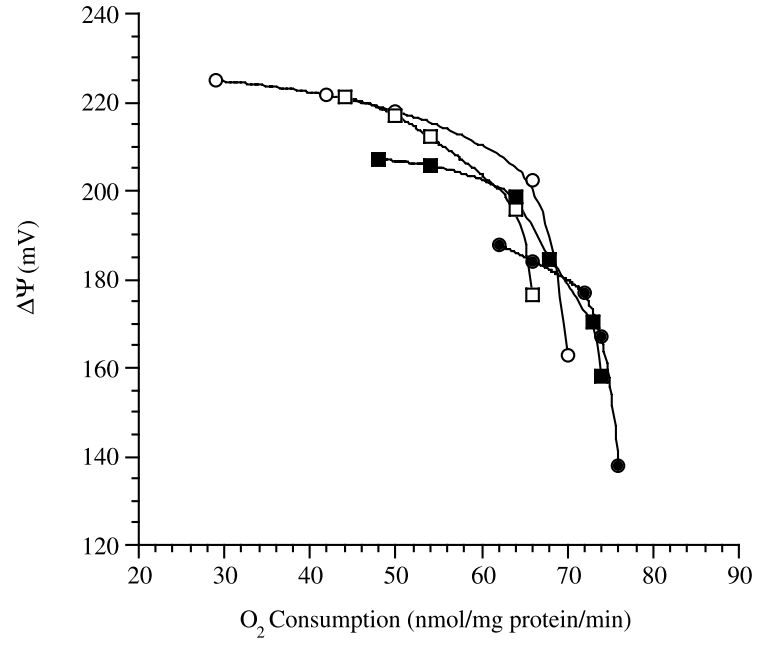

Fig. 6. Effect of OHTAM on the kinetic response of $\Delta p$ generators to $\Delta \Psi$. Nonphosphorylating mitochondria $(1 \mathrm{mg})$ suspended in $1 \mathrm{ml}$ of the standard respiratory medium supplemented with nigericin (50 $\mathrm{ng} / \mathrm{mg}$ protein), oligomycin (1 $\mu \mathrm{g} / \mathrm{ml}), 2 \mu \mathrm{M}$ rotenone and $4 \mu \mathrm{M} \mathrm{TPP}^{+}$were incubated at $25{ }^{\circ} \mathrm{C}$ for $3 \mathrm{~min}$ in the absence $(\bigcirc)$ and presence of $20(\square), 40$ (घ) and 60 (O) nmol OHTAM/mg protein. Mitochondrial respiration and $\Delta \Psi$ were measured simultaneously with a Clark-type $\mathrm{O}_{2}$ electrode and a $\mathrm{TPP}^{+}$sensitive electrode, respectively, and were placed in the same closed reaction chamber. The reactions were started with $5 \mathrm{mM}$ succinate and after a steady-state distribution of $\mathrm{TPP}^{+}$, mitochondrial suspensions were titrated by sequential additions of FCCP (10 $\mathrm{nM}$ ). The results are typical of six different experiments performed with three different mitochondrial preparations.

mitochondria, respectively. In contrast, TAM at concentrations of 25 and $50 \mathrm{nmol} / \mathrm{mg}$ protein disrupts 66 and $80 \%$ of the mitochondrial population, respectively, pointing out that this anticancer drug induces a much stronger disruptive effect on the mitochondrial membrane structure (Fig. 9).

The concentrations of OHTAM usually reached in blood plasma after therapeutic administration are about $3-5 \mathrm{ng} / \mathrm{ml}$ (Lien et al., 1987; McCague et al., 1990), although recently it has been reported that OHTAM attained in rat serum a $C_{\max }$ of $385 \pm 132 \mathrm{ng} / \mathrm{ml}(0.9 \mu \mathrm{M})$ after s.c. administration of a second dose of TAM at $1 \mathrm{mg} / \mathrm{kg}$ (Mandlekar et al., 2000). Owing to its high hydrophobic character and partition into biological membranes (Custódio et al., 1991), the levels of OHTAM in humans are 10- to 60-fold higher in tissues than in plasma (Lien et al., 1991). Therefore, the therapeutics with OHTAM may cause tissue concentra- 


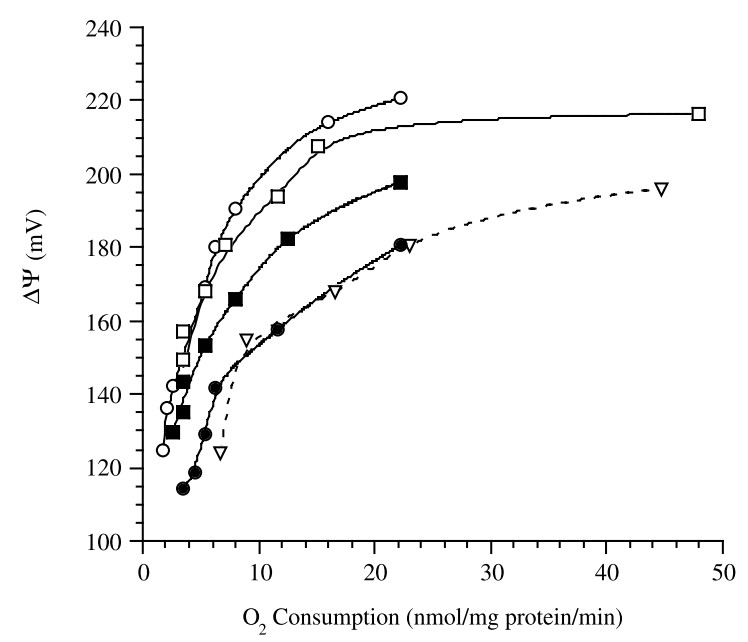

Fig. 7. Effect of OHTAM on the proton leak of nonphosphorylating mitochondria. Mitochondria were incubated in the absence $(\bigcirc)$ and presence of $20(\square), 40(\square)$ and $60(\bigcirc)$ $\mathrm{nmol}$ OHTAM/mg or $20 \mathrm{nmol} \mathrm{TAM} / \mathrm{mg}$ protein for comparison ( $\nabla$-dashed line). Experiments were performed as described in Fig. 6, except that mitochondria suspensions were titrated by sequential additions of malonate, a respiratory inhibitor. The results are representative of four independent experiments.

tions similar to those observed for TAM $(\sim 50$ $\mu \mathrm{M})$ since the partitioning of OHTAM into membranes is significantly higher than that of TAM (Custódio et al., 1991). However, it is worthy of notice that, in this study we have also used higher concentrations only to compare the effects of this metabolite with those previously reported for TAM (Cardoso et al., 2001).

\section{Discussion}

Mitochondria serve as sensors of the xenobioticinduced toxicity that ultimately leads to cellular disassembly (Wallace and Starkov, 2000). Recently, we have reported that TAM-induced alteration of mitochondrial bioenergetic capacity may be involved in its antiproliferative ER-independent activity and side effects on different cells types (Cardoso et al., 2001).

In the present study, we evaluated the effects of OHTAM, recognized to be more active and possessing several hundred times more affinity to the ER than TAM, on mitochondrial bioenergetic

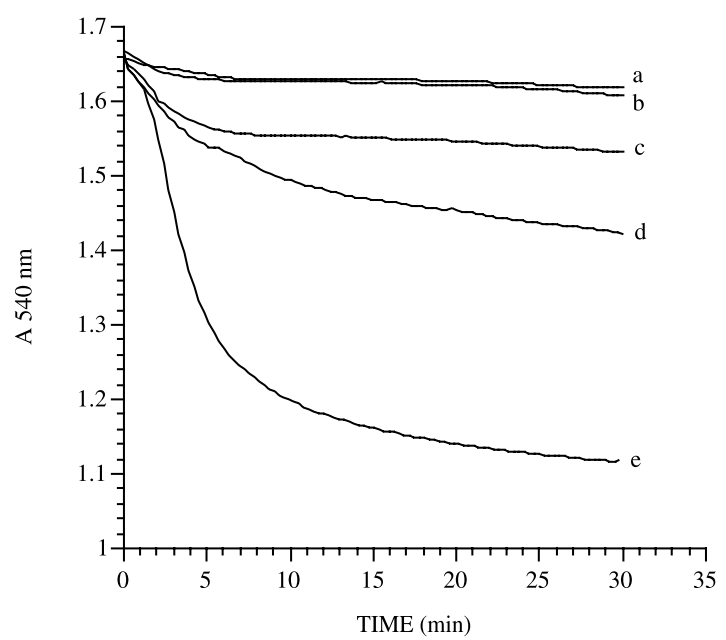

Fig. 8. Effects of OHTAM and TAM on mitochondrial swelling. The experiments were performed in $2 \mathrm{ml}$ of reaction medium containing $200 \mathrm{mM}$ sucrose, $10 \mathrm{mM}$ Tris-Mops ( $\mathrm{pH}$ 7.4), $1 \mathrm{mM} \mathrm{KH}_{2} \mathrm{PO}_{4}$ and $10 \mu \mathrm{M}$ EGTA. Mitochondria $(0.5 \mathrm{mg} /$ $\mathrm{ml}$ ) were incubated at $30{ }^{\circ} \mathrm{C}$ for $3 \mathrm{~min}$ in the absence (a) and presence of 10 (b), 30 (c), 50 (d) nmol OHTAM/mg protein or $50 \mathrm{nmol} \mathrm{TAM} / \mathrm{mg}$ protein (e). The traces, obtained by following the light scattering at $540 \mathrm{~nm}$, are typical of three separate experiments with different mitochondrial preparations.

functions. As reported for TAM, OHTAM depresses the oxidative phosphorylation capacity of liver mitochondria in a concentration-dependent way, as deduced from a decrease of respiratory coefficient and of the ADP/O ratio (Fig. 1), but TAM has expressed much more potent effects (Cardoso et al., 2001). Moreover, OHTAM slightly depresses the mitochondrial $\Delta \Psi$ (Fig. 2) and the state 3 respiration (Figs. 1 and 2) but induces stimulation of state 4 respiration (Fig. 4) as a function of concentration that also reflect a partial impairment of the phosphorylation efficiency of mitochondria. However, as opposed to TAM that promotes a strong inhibition of the oxidative phosphorylation of added ADP, as shown in Fig. 3 and also according to our previous results (Cardoso et al., 2001), the phosphorylation efficiency of mitochondria is not significantly affected by OHTAM (Fig. 1). This is also inferred from the fluctuations associated with the ADPinduced phosphorylative cycle (Fig. 2) and from the effects on $\mathrm{pH}$ changes associated with ATP synthesis (Fig. 3). 


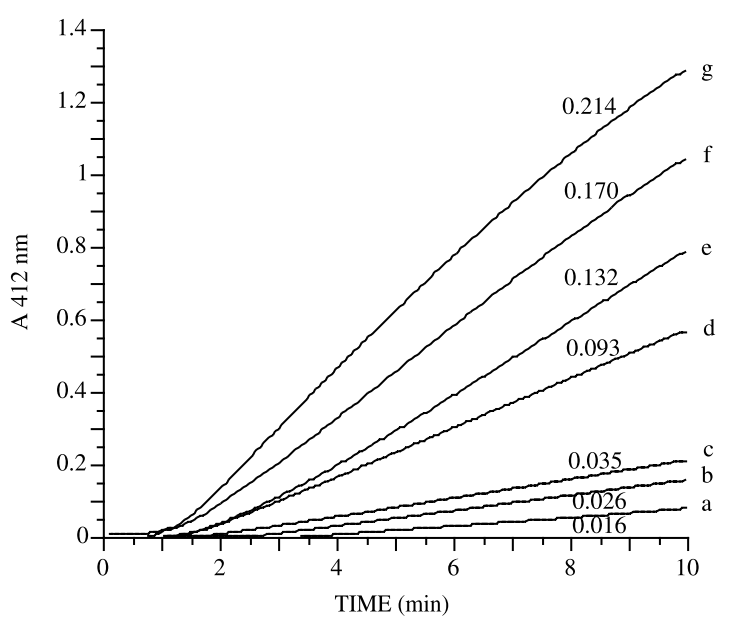

Fig. 9. Comparison of OHTAM and TAM effects on citrate synthase activity of intact mitochondria. The citrate synthase activity was measured in $2 \mathrm{ml}$ of reaction medium containing $100 \mathrm{mM}$ Tris (pH 8) and supplemented with $200 \mu \mathrm{M}$ 5,5'-dithiobis(2-nitrobenzoic acid) and $200 \mu \mathrm{M}$ acetylCoA. After incubation of mitochondria $(100 \mu \mathrm{g})$ at $30{ }^{\circ} \mathrm{C}$ for $3 \mathrm{~min}$ in the absence (a) and presence of either 10 (b), 25 (c), 50 (d) nmol OHTAM/ $\mathrm{mg}$ protein, or 25 (e) and 50 (f) $\mathrm{nmol} \mathrm{TAM} / \mathrm{mg}$ protein or $0.1 \%$ Triton (g), the reactions were started by adding $100 \mu \mathrm{M}$ oxaloacetic acid. The citrate synthase activity expressed in $\mu \mathrm{mol} / \mathrm{min} / \mathrm{mg}$ protein, as indicated by the values adjacent to the traces, was followed by the increase in absorbance at $412 \mathrm{~nm}$ as function of time. The recordings are representative of four different mitochondrial preparations.

The OHTAM-induced increase in the respiratory rate in state 4 that parallels the partial collapse of the $\Delta \Psi$ (Fig. 4) and the decrease of the ADP phosphorylation indicate an uncoupling effect of this drug on the oxidative phosphorylation system. The observed partial uncoupling effect observed is probably due to a slight permeabilization of the mitochondrial inner membrane to protons as confirmed by the Brand approach (Fig. 7). This effect could be related with a protonophoretic action and/or a nonspecific membrane permeabilization induced by this tertiary-amine antiestrogen (Murphy, 1989). In fact, a proton shuttle mechanism has been proposed to explain the ability of some tertiary-amine local anesthetics and other amine compounds to uncouple oxidation from phosphorylation (Garlid and Nakashima, 1983). Similarly, this mechanism could also explain the uncoupling effect of OHTAM, since the amine group of this drug can bind and translocate protons across the mitochondrial inner membrane due to its high lipophilic character and strong partition into biomembranes (Custódio et al., 1991). Moreover, the charged protonated form of OHTAM, preferentially located in the outer regions of the bilayer (Custódio et al., 1993), could be membrane-permeable and determine the increase in proton leak, acting in low concentrations like a classic protonophore. In addition to its uncoupling effect, the ionizable group of $\mathrm{OH}$ TAM, by changing the membrane surface potential, may induce a nonspecific inhibition of the phosphorylation system and a specific inhibition of either the adenine nucleotide translocator or the phosphate transporter. Further studies, currently in progress, are obviously required to assess these hypotheses focused on the membrane transporters. Both suggestions could explain the decrease in the oxidative phosphorylation capacity and the partial collapse of the $\Delta \Psi$ due to proton leak that parallels the stimulation of state 4 respiration rate (Fig. 4), as previously reported for several lipophilic compounds possessing base- or aciddissociative groups (Garlid and Nakashima, 1983; Fromenty et al., 1990; Keller et al., 1992). However, it cannot be excluded that the uncoupling action of OHTAM, at high concentrations, might be due to a nonspecific increase in the membrane permeability as a consequence of the mitochondrial membrane disruption.

To assess the relationship between the proton leak and ultrastructural changes induced by $\mathrm{OH}-$ TAM, the stimulated ATPase activity was measured in intact mitochondria pre-incubated with this drug (Fig. 5). Furthermore, the OHTAM effects on mitochondrial swelling (Fig. 8) and on the citrate synthase activity of intact mitochondria (Fig. 9) were also evaluated. OHTAM at high concentrations stimulates ATPase activity of intact mitochondria, but to a smaller degree than FCCP or TAM (Fig. 5) which induces membrane disruption as previously described (Chen et al., 1999; Cruz Silva et al., 2000; Cardoso et al., 2001). Moreover, the decrease in light scattering of nonenergized mitochondria (Fig. 8) and the stimulation of citrate synthase (Fig. 9) induced by OHTAM, together with the previous data demonstrating the release of $\mathrm{Ca}^{2+}$ by SR (Custódio et al., 
1996) and of $\mathrm{K}^{+}$from erythrocytes (Cruz Silva et al., 2001), point to the membrane permeabilization ability of this drug. Therefore, at low concentrations OHTAM may promote membrane permeabilization to protons by acting as a proton shuttle, whereas TAM has showed to induce a much more potent proton leak (Fig. 7). At high concentrations, OHTAM partially uncouples oxidative phosphorylation due to a slight permeabilization related with the disruption of the structural integrity of the mitochondrial inner membrane. Besides the increase in the membrane permeability to protons, the inhibition of respiration induced by this drug at high concentrations (Fig. 6) may contribute to the understanding of the mechanism underlying its depressive effect on $\Delta \Psi$.

In conclusion, our results suggest that OHTAM slightly affects the mitochondrial bioenergetic functions, inducing a partial uncoupling of the oxidative phosphorylation system, in contrast with the deleterious effects of TAM in rat liver mitochondria (Cardoso et al., 2001). The low depressive effect of OHTAM on $\Delta \Psi$ may activate the apoptotic machinery of cytochrome $\mathrm{c}$ release, leading to induction of caspase-dependent apoptosis. Moreover, these data indicate that OHTAM is much less toxic to mitochondria than TAM, in agreement with the different effects of both drugs in human erythrocytes (Cruz Silva et al., 2000, 2001) and with the different apoptotic effects in p53(-) human mammary epithelial cells (Dietze et al., 2001).

\section{Acknowledgements}

This work was supported by Sapiens 99/36075/ 99 research program and Carla M.P. Cardoso is a grant recipient from Praxis XXI (Praxis/BD/ 21600/99).

\section{References}

Ault, A., Brandbury, J., 1998. Experts argue about tamoxifen prevention trial. Lancet 351, 1107.
Borgna, J.-L., Rochefort, H., 1981. Hydroxylated metabolites of tamoxifen are formed in vivo and bound to estrogen receptor in target tissues. J. Biol. Chem. 256, 859-868.

Brand, M.D., 1990. The proton leak across the mitochondrial inner membrane. Biochim. Biophys. Acta 1018, 128-133.

Cardoso, C.M.P., Custódio, J.B.A., Almeida, L.M., Moreno, A.J.M., 2001. Mechanisms of the deleterious effects of tamoxifen on mitochondrial respiration rate and phosphorylation efficiency. Toxicol. Appl. Pharmacol. 176, 145-152.

Chance, B., Williams, G.R., 1956. The respiration chain and oxidative phosphorylation. Adv. Enzymol. 17, 65-134.

Chen, Y., Schindler, M., Simon, S.M., 1999. A mechanism for tamoxifen-mediated inhibition of acidification. J. Biol. Chem. 274, 18364-18373.

Ching, C.K., Smith, P.G., Long, R.G., 1992. Tamoxifen associated hepatocellular damage and agranulocytosis. Lancet 339, 940.

Cruz Silva, M.M., Madeira, V.M.C., Almeida, L.M., Custódio, J.B.A., 2000. Hemolysis of human erythrocytes induced by tamoxifen is related to disruption of membrane structure. Biochim. Biophys. Acta 1464, 49-61.

Cruz Silva, M.M., Madeira, V.M.C., Almeida, L.M., Custódio, J.B.A., 2001. Hydroxytamoxifen interaction with human erythrocyte membrane and induction of permeabilization and subsequent hemolysis. Toxicol. In Vitro 15, 615-622.

Custódio, J.B.A., Almeida, L.M., Madeira, V.M.C., 1991. A reliable and rapid procedure to estimate drug partitioning in biomembranes. Biochem. Biophys. Res. Commun. 176, $1079-1085$.

Custódio, J.B.A., Almeida, L.M., Madeira, V.M.C., 1993. The active metabolite hydroxytamoxifen of the anticancer drug tamoxifen induces structural changes in membranes. Biochim. Biophys. Acta 1153, 308-314.

Custódio, J.B.A., Almeida, L.M., Madeira, V.M.C., 1996. The effect of the anti-cancer drugs tamoxifen and hydroxytamoxifen on the calcium pump of isolated sarcoplasmic reticulum vesicles. Toxicol. In Vitro 10, 523-531.

Custódio, J.B.A., Moreno, A.J.M., Wallace, K.B., 1998. Tamoxifen inhibits induction of the mitochondrial permeability transition by $\mathrm{Ca}^{2+}$ and inorganic phosphate. Toxicol. Appl. Pharmacol. 152, 10-17.

Dietze, E.C., Caldwell, L.E., Grupin, S.L., Mancini, M., Seewaldt, V.L., 2001. Tamoxifen but not 4-hydroxytamoxifen initiates apoptosis in p53(-) normal human mammary epithelial cells by inducing mitochondrial depolarization. $\mathbf{J}$. Biol. Chem. 276, 5384-5394.

Early Breast Cancer Trialists' Collaborative Group, 1998. Tamoxifen for early breast cancer: an overview of the randomized trials. Lancet 351, 1451-1467.

Ferreira, F.M.L., Madeira, V.M.C., Moreno, A.J., 1997. Interactions of 2,2-bis ( $p$-chlorophenyl)-1,1-dichloroethylene with mitochondrial oxidative phosphorylation. Biochem. Pharmacol. 53, 299-308.

Fromenty, D., Fisch, C., Person, A., Letteron, P., Larrey, D., Pessayre, D., 1990. Dual effect of amiodarone on mitochondrial respiration. Initial protonophoric uncoupling effect followed by inhibition of the respiratory chain at the levels 
of complex I and complex II. J. Pharmacol. Exp. Ther. 255, 1377-1384.

Fusi, F., Sagarali, G., Murphy, M.P., 1992. Interaction of butylated hydroxyanisole with the mitochondrial oxidative phosphorylation. Biochem. Pharmacol. 43, 1203-1208.

Garlid, K.D., Nakashima, R.A., 1983. Studies on the mechanism of uncoupling by amine local anesthetics, evidence for mitochondrial proton transport mediated by lipophilic ion pairs. J. Biol. Chem. 258, 7974-7980.

Gornall, A.G., Bardawill, C.J., David, M.M., 1949. Determination of serum proteins by means of the biuret reaction. $\mathrm{J}$. Biol. Chem. 177, 751-766.

Hafner, R.P., Brown, G.C., Brand, M.D., 1990. Thyroidhormone control of state-3 respiration in isolated rat liver mitochondria. Biochem. J. 265, 731-734.

Hafner, R.P., Brand, M.D., 1991. Effect of proton motive force on the relative stoichiometries of the mitochondrial proton pumps. Biochem. J. 275, 75-80.

Jordan, V.C., Koch, R., Langan, S., McCague, R., 1988. Ligand interaction at the estrogen receptor to program antiestrogen action: a study with non-steroidal compounds in vitro. Endocrinology 122, 1449-1454.

Jordan, V.C., 1990. Long-term adjuvant tamoxifen therapy for breast cancer. Breast Cancer Res. Treat. 15, 125-136.

Kamo, N., Maratsugu, M., Hongoh, R., Kobatabe, Y., 1979. Membrane potential of mitochondria measured with an electrode sensitive to tetraphenylphosphonium and relationship between proton electrochemical potential and phosphorylation potential in steady state. J. Membr. Biol. 49, $105-121$.

Kargacin, M.E., Ali, Z., Ward, C.A., Pollock, N.S., Kargacin, G.J., 2000. Tamoxifen inhibits $\mathrm{Ca}^{2+}$ uptake by the cardiac sarcoplasmic reticulum. Eur. J. Physiol. 440, 573-579.

Keller, B.J., Marsman, D.S., Popp, J.A., Thurman, R.G., 1992. Several nongenotoxic carcinogen uncouple mitochondrial oxidative phosphorylation. Biochim. Biophys. Acta 1102, 237-241.

Lien, E.A., Ueland, P.M., Solheim, E., Kvinnsland, S., 1987. Determination of tamoxifen and four metabolites in serum by low-dispersion liquid chromatography. Clin. Chem. 33, $1608-1614$

Lien, E.A., Solheim, E., Ueland, P.M., 1991. Distribution of tamoxifen and its metabolites in rat and human tissues during steady-state treatment. Cancer Res. 51, 4837-4844.

Lionetti, L., Iossa, S., Liverni, G., Brand, M.D., 1998. Changes in the hepatic mitochondrial respiratory system in the transition from weaning to adulthood in rats. Arch. Biochem. Biophys. 352, 240-246.

Loeffler, M., Kroemer, G., 2000. The mitochondrion in cell death control: certainties and incognita. Exp. Cell Res. 256, $19-26$.

Madeira, V.M.C., Antunes-Madeira, M.C., Carvalho, A.P., 1974. Activation energies of the ATPase activity of sarco- plasmic reticulum. Biochem. Biophys. Res. Commun. 58, 897-904.

Mandlekar, S., Hebbar, V., Christov, K., Kong, A.-N.T., 2000. Pharmacodinamics of tamoxifen and its 4-hydroxy and $\mathrm{N}$ desmethyl metabolites: activation of caspases and induction of apoptosis in rat mammary tumors and in human breast cancer cell lines. Cancer Res. 60, 6601-6606.

Mauvais-Jarvis, P., Baudot, N., Castaigne, D., Banzet, P., Jutten, F., 1986. Trans 4-hydroxytamoxifen concentration and metabolism after local percutaneous administration to human breast. Cancer Res. 46, 1521-1525.

McCague, R., Parr, I.B., Leclercq, G., Leung, O.-T., Jarman, M., 1990. Metabolism of tamoxifen by isolated rat hepatocytes. Identification of the glucuronide of 4-hydroxytamoxifen. Biochem. Pharmacol. 39, 1459-1465.

Moreno, A.J.M., Madeira, V.M.C., 1991. Mitochondrial bioenergetics as affected by DDT. Biochim. Biophys. Acta 1060, $166-174$

Murphy, M.P., Brand, M.D., 1987. The control of the electron flux through cytochrome c oxidase. Biochem. J. 243, 499505.

Murphy, M.P., 1989. Slip and leak in mitochondrial oxidative phosphorylation. Biochim. Biophys. Acta 977, 123-141.

Osborne, C.K., Wiebe, V.J., McGuire, W.L., Ciocca, D.R., DeGregorio, M.W., 1992. Tamoxifen and the isomers of 4hydroxytamoxifen in tamoxifen resistant tumors from breast cancer patients. J. Clin. Oncol. 10, 304-310.

Pujol, H., Girault, J., Rouanet, P., Fournier, S., Grenier, J., Simony, J., Fourtillan, J.-B., Pujol, J.-L., 1995. Phase I study of percutaneous 4-hydroxytamoxifen with analyses of 4-hydroxytamoxifen concentrations in breast cancer and normal breast tissue. Cancer Chemother. Pharmacol. 36, 493-498.

Sauvez, F., Drouin, D.S., Attia, M., Bertheux, H., Forster, R., 1999. Cutaneously applied 4-hydroxytamoxifen is not carcinogenic in female rats. Carcinogenesis 20, 843-850.

Shepherd, D., Garland, P.B., 1969. Citrate synthase from rat liver. Methods Enzymol. 13, 11-16.

Suwalsky, M., Hernandez, P., Villena, F., Auilar, F., Sotomayor, C.P., 1998. Interaction of the anticancer drug tamoxifen with the human erythrocyte membrane and the molecular models. Z. Naturforsh. Sect. C Biosci. 53, 182190.

Trounce, I.A., Kim, Y.L., Jun, A.S., Wallace, D.C., 1996. Assessment of mitochondrial oxidative phosphorylation in patient muscle biopsies, lymphoblasts and transmitochondrial cell lines. Methods Enzymol. 264, 484-509.

Wallace, K.B., Eells, J.T., Madeira, V.M.C., Cortopassi, G., Jones, D.P., 1997. Mitochondria-mediated cell injury. Fundam. Appl. Toxicol. 38, 23-37.

Wallace, K.B., Starkov, A.A., 2000. Mitochondrial targets of drug toxicity. Annu. Rev. Pharmacol. Toxicol. 40, 353-388. 